\title{
Introduction for synthese special issue causation in the metaphysics of science: natural kinds
}

\author{
Andrew McFarland ${ }^{1}$
}

Received: 10 November 2017 / Accepted: 11 November 2017 / Published online: 27 November 2017

(C) Springer Science+Business Media B.V., part of Springer Nature 2017

\section{Introduction}

Several of the essays in this special issue began as presentations given at a workshop entitled The Metaphysics of Science: Causation and Natural Kinds, which was held March 20-21, 2014, at the Institute for the History and Philosophy of Science and Technology, University of Paris 1, Panthéon-Sorbonne, CNRS. The issue is intended to consolidate the burgeoning new movement known as the metaphysics of science. It focuses on tackling specific metaphysical topics, namely natural kinds, from a causal approach, and in an empirically informed manner. The strategy is to maintain as close contact as possible between metaphysical inquiry and inquiry in the philosophy of science. This issue brings together a number of essays devoted to a discussion of the relationship between causation and natural kinds from within the framework of the metaphysics of science. To this end the proposed special issue brings together both philosophers of science interested in specific metaphysical notions like cause and kind, as well as metaphysicians interested in the metaphysical implications of scientific practice and inquiry.

In recent years, topics like causation and natural kind have received much attention from both metaphysicians and philosophers of science (Bird 2007; Cartwright 2002; Khalidi 2013; Maudlin 2007; Mumford et al. 2013; Mumford and Anjum 2011; Woodward 2003, etc.). This new interest in the metaphysics of science stems from the desire to understand both the roles those notions play within scientific practice and the manner in which evidence from the natural sciences can inform metaphysical inquiry (Ladyman and Ross 2009).

\footnotetext{
Andrew McFarland

andrewlmcfarland@gmail.com

1 City University of New York, New York City, NY, USA
} 
The subject of causation in particular has received much philosophical attention over the years-(Armstrong 1997; Davidson 1980; Harré and Madden 1975; Lewis 1986; Mackie 1965; Russell 1913)_but only more recently has inquiry into the metaphysics of causation made significant contact with the philosophy of science. The question of the form and validity of causal inference (Pearl 2000; Spirtes et al. 2000) was for some time investigated separately from metaphysical discussions. The latter tended to revolve around the question of the nature of the causation relation itself (debates between process theories of causation, counterfactual theories, primitivist theories, etc.). However, recent debates concerning the role of causation in the special sciences have shown how metaphysical considerations play a direct role in the constitution of scientific practices in the special science. Theories like manipulationism (Woodward 2003) for instance, which elaborates on advances in our formal understanding of causal inference in the sciences, delivered important insights to those interested in the metaphysical nature of causation.

A renewed sense of the centrality of causation has been critical to making sense of other classical metaphysical notions, such as natural kinds. For example, the homeostatic property cluster concept as sketched by Boyd (1999a, b) has been criticized for being too restrictive in that it fails to take into account diachronic causal connections as they are addressed and captured by the specific sciences [see for example Ereshefsky and Matthen (2005) for the case of biological kinds]. However, causal theories of natural kinds can be developed in a way that would be relevant both for metaphysics and philosophy of science. In the same way, issues about individuality (Dorato and Morganti 2013; Clarke 2010; Bouchard et al. 2013; Pradeu 2012) have been addressed on the basis of an analysis of the way scientific theories in specific ontological domains actually individualize things.

The essays in this short special issue are organized in the following way. Muhammad Ali Khalidi elaborates on his claim that natural kinds are "nodes in causal networks". According to Khalidi, the projectibility of natural kind predicates is explained by the fact that there are hierarchies of properties associated with natural kinds-a core set, and a derivative set. When the core set is suitably clustered, and under the rights sorts of background conditions, these causally give rise to the instantiation of the more derivative set. Alexander Bird considers several metaphysical views concerning natural kinds, and addresses how these views relate to the thesis of natural kind essentialism. He argues that natural kind essentialism is committed to the existence of natural kinds, and concludes with a discussion of Boyd's homeostatic property cluster view. P. D. Magnus distinguishes between two questions about natural kinds, what he calls the taxonomy question and the ontology question, and argues that philosophers have systematically conflated the two. In confusing these two questions, Magnus shows how this has led to an overemphasis on the concept of similarity. Andrew McFarland addresses the question of how to ontologically characterize a certain class of natural kind, namely isomeric chemical kinds. Following a line of hylomorphic argumentation, McFarland argues that metaphysicians may have reason for supposing that certain chemical kinds may have structural proper parts, and causal-cum-dispositional parts as well. Françoise Longy argues for a variety of natural kind pluralism - the view that there are at least two sorts of natural kind, scientific kind on the one hand, and common kinds on the other. Longy does this by focus- 
ing on the case of the term "jade", which no applies to two distinct chemical kinds, jadeite and nephrite. Longy goes on to argue that current theories of natural kind fail to accommodate this history, and that by the criteria specified by main theories of natural kind terms, "jade" counts as a natural kind term. She concludes that the kind picked out by "jade" is indeed a natural kind. Finally, Matthew Slater examines whether ecosystems might be regarded as natural kinds, arguing that accounts emphasizing nomic or causal-mechanistic explanations fair poorly at accommodating ecosystemic kinds. Drawing from his previous work on stable property cluster kinds, Slater argues that this approach can make room for contingent anchoring displayed by ecosystems.

This issue is progressive and forward-looking. The issue is intended to help consolidate the emerging field of the metaphysics of science. The subjects of causation, natural kinds, and individuality have benefitted from being informed by both a close attention to advancements in scientific practice, and the recognition that traditional metaphysical notions like causation are integral to certain scientific discussions. It is hoped that this issue aids in furthering this collaborative spirit.

\section{References}

Armstrong, D. (1997). A world of states of affairs. Cambridge: Cambridge University Press.

Bird, A. (2007). Natures metaphysics. Oxford: Oxford University Press.

Bouchard, F., \& Huneman, P. (Eds.). (2013). From groups to individuals: Evolution and emerging individuality. Cambridge, MA: MIT Press.

Boyd, R. (1999a). Species: New interdisciplinary essays. In R. Wilson (Ed.), Homeostasis, species, and higher taxa (pp. 141-185). Cambridge, MA: MIT Press.

Boyd, R. (1999b). Kinds, complexity and multiple realization: Comments on Millikan's 'historical kinds and the special sciences'. Philosophical Studies, 95, 67-98.

Cartwright, N. (2002). Against modularity, the causal Markov condition, and any link between the two: Comments on Hausman and Woodward. British Journal for the Philosophy of Science, 53, 411-453.

Clarke, E. (2010). The problem of biological individuality. Biological Theory, 5(4), 312-325.

Davidson, D. (1980). "Actions, reasons, and causes", orig. 1963, essays on actions and events (pp. 3-19). Oxford: Clarendon Press.

Dorato, M., \& Morganti, M. (2013). Grades of individuality: A pluralistic view of identity in quantum mechanics and in the sciences. Philosophical Studies, 163(3), 591-610.

Ereshefsky, M., \& Matthen, M. (2005). Taxonomy, polymorphism, and history: An introduction to population structure theory. Philosophy of Science, 72, 1-21.

Harré, R., \& Madden, E. (1975). Causal powers: A theory of natural necessity. Oxford: Basil Blackwell.

Khalidi, M. A. (2013). Natural categories and human kinds: Classification in the natural and social sciences. Cambridge: Cambridge University Press.

Ladyman, J., Ross, D., et al. (2009). Everything must go: Metaphysics naturalized. Oxford: Oxford University Press.

Lewis, D. (1986). Causation philosophical papers (Vol. 2, pp. 159-213). Oxford: Oxford University Press.

Mackie, J. L. (1965). Causes and conditions. American Philosophical Quarterly, 2, 245-264.

Maudlin, T. (2007). The metaphysics within physics. Oxford: Oxford University Press.

Mumford, S., \& Anjum, R. (2011). Getting causes from powers. Oxford: Oxford University Press.

Mumford, S., \& Tugby, M. (Eds.). (2013). Metaphysics and science. Oxford: Oxford University Press.

Pearl, J. (2000). Causality: Models, reasoning, and inference. Cambridge: Cambridge University Press.

Pradeu, T. (2012). The limits of the self: Immunology and biological identity. Oxford: Oxford University Press.

Russell, B. (1913). On the notion of cause. Proceedings of the Aristotelian Society, 13, 1-26. 
Spirtes, P., Glymour, C., \& Scheines, R. (2000). Causation, prediction and search (2nd ed.). Cambridge, MA: MIT Press.

Woodward, J. (2003). Making things happen: A theory of causal explanation. Oxford: Oxford University Press. 